\title{
On the problem of Defining Manga: A Study of the Influence of Taoism and Zen Buddhism on Manga Aesthetics
}

\author{
Tiago Canário \\ Korea University
}

How can manga, or the so-called manga style, be defined? Is it possible to talk about a manganess that characterizes such a huge variety of works? The term manga undoubtedly addresses a national and cultural issue. After all, mangas are Japanese comics. But are they only that? Can we not talk about nonJapanese mangas? It is a fact that many artists, editors, and other agents related to the comics industry around the world argue in favor of a "manga style" that exceeds Japanese borders. Readers from different countries often look at national works and define their experience as similar to that of reading a manga.

In recent decades we have seen both underground and commercial best-sellers from the United States, Philippines, Brazil, and France labeled as "manga", or something in-between (Brienza). How can we define these hits and what do they have in common - if they do share some particularity? In an attempt to categorize such new art, artists, scholars, editors, and journalists have proposed terms such as euromanga, amerimanga, manfra, nouvelle manga, global manga, and so on. This paper contributes to the discussion from a philosophical perspective, drawing on ancient Eastern traditions to approach what such an experience of reading manga could be.

First, it is worth saying that despite being focused on formal aesthetic properties of mangas, this paper does not draw their chronological timeline. Many scholars have already traced the roots of manga back to the traditional arts of e-makimono and ukiyo-e (e.g., L'univers des mangas, Lamarre, Moliné). The examples in this article, however, came from recent international productions, which are the fruits of a later artistic revolution conducted by Osamu Tezuka`s works (Gravett, McCarthy).

There are also many studies of a particular repertoire of cartooning style, through topics such as the representation of emotions (Abbott and Forceville), or JVL, i.e., Japanese visual language (Cohn, Cohn and Ehly). Such scholarship is related to questions that have emerged from the visual impact of manga on Western publics. If books have been published under the how-todraw-manga label to fulfill readers' interests, the exaggerated depiction of 
human emotions and typical character design have also attracted the attention of academics.

Moving further from the study of individual images, Cohn affirms that "[...] the real power of language comes from its sequence - combining multiple units to create a cohesive meaning greater than its individual parts" (194). Comics are a system based on a grammar. When analyzing this particular grammar of JVL, Cohn refers to McCloud, to whom is attributed the already popular idea of one of the main features of mangas narratives, aspect-to-aspect panel transitions - those in which the narrative seems to suspend time or slow it down to show different aspects of the environment ${ }^{1}$. McCloud states that mangas are usually less "goal-oriented" than western works, putting emphasis on being there, not on getting there. How can we systematically grasp the Japanese notion of being there?

There are, of course, many possible ways to approach such a question. Answers can arise from ideological, economic, industrial, transcultural, and artistic factors. Each of them offers different perspectives and arguments, but we will prioritize a philosophical one. The following sections discuss manga by looking at how thoughts on social and personal practices developed by ancient Eastern traditions, which deal with how individuals relate to the Cosmos, have been translated into art.

When dealing with (or discussing, analyzing, evaluating, etc.) the Japanese case, Yuriko Saito proposes that Western audiences got closer to Japanese aesthetics at the turn of the $20^{\text {th }}$ century, because of classic essays published in foreign languages. In this regard we can highlight the importance of Kakuzo Okakura's The Book of Tea, first published in 1907. In his work, Okakura introduces the traditional ceremony of tea through a discussion on how Taoism and Zen can be seen in Japanese ideals of beauty and perfection. Looking at art would be looking at the confluence of Japanese thought. The art of tea is a way to experience life, whose truth and authenticity should be reached by nourishing moral and aesthetic sensibility.

\footnotetext{
${ }^{1}$ Considering the multiplicity of cases and their particularities, the inclusion of such panel transitions could be related to economic issues more than to artistic ones - in other words, as a way to enable the extension of narratives to follow an industrial rhythm of production more than as a way to express artistic preferences. Despite specific reasons or influences, however, one can still consider those panel transitions from the perspective of the effect they have on reading processes. Assuming the recipient's point of view, the regular presence of such panel transitions in many Japanese narratives can be taken as a textual strategy to create moods and highlight emotional moments.
} 
Okakura suggests paying particular attention to Taoism and Zen for their ability to translate ideas from life to death. The study of both philosophies would be the study of essential components of Japanese aesthetics, moral values, and commitment. From that, his work can be a valuable starting point for this essay. This paper proposes to investigate Eastern philosophies as one of the possible ways to define the style of narrative created by Japanese artists, which could also offer an alternative understanding of foreign manga-like productions. To that end, this paper focuses on four specific topics: the Tao and Zen influence on art; the Japanese artistic notions of fluidity and rhythm; the definition of mangas; and the specificity of manga-like narratives.

\section{Tao and Zen influence on art}

"The reality of a room [...] was to be found in the vacant space enclosed by the roof and the walls, not in the roof and walls themselves. The usefulness of a water pitcher dwelt in the emptiness where water might be put, not in the form of the pitcher or the material of which it was made. Vacuum is all potent because all containing" (Okakura 9). This is how Okakura presents the metaphor of vacuum, recalling Lao-Tsé's ideas to explain the place (or nonplace) in which we can find the essence of everything. The vacuum contains every possibility, and this is its potential force. But why is it important?

Particularly in art, the principle was translated into the value of suggestion, which is conceived as an artistic economy directed to incompleteness. In other words, Japanese art forms are incomplete in order to offer space to readers, who can therefore complete them. As Okakura explains: "A vacuum is there for you to enter and fill up the full measure of your aesthetic emotion" ("Taoism and Zennism" para. 10). The idea of suggestion is then no less than our possibility. Such use might not be exclusive to Japanese art, but it is fundamental to it.

In a study on the moral dimension of Japanese aesthetics, Saito argues that such tradition is notable for its "[...] sensitivity to, respect for, and appreciation of the quintessential character of an object" (85), an attitude embodied whether in garden design, cooking, or painting. Since Japanese art forms are not subject-governed, but object-centered, omissions, or the effect of incompleteness, are assumed as a way to present essential aspects of the object.

Saito argues that this aesthetic tradition expresses its concerns through designs that respond to a particular temporal sequence of our sensual 
experience. It applies spatial arrangement and sequential order to offer a way for our experience to unfold while inviting us to actively take part in it. It offers not only an empty space for us, but one in which we grow together with the object itself. In opposition to Anglo-European cultures, functional efficiency is not the goal. We face a miekagure strategy, or Zen view of "now we see it, now we don't', rather than a linear, clear, and objective way.

If Japanese art forms were strongly influenced by ideas of immersion, vacuum, and suggestion, mangas are not an exception. It is no wonder Paul Grave suggests that "[...] in Western comics we read what happened next; in manga, we read what is happening right now" (apud "The Monstrator, the Recitant"). The author highlights how such a narrative economy makes use of specific techniques to immerse readers into the stories. On the one hand, the main narrative traditions from the West have traditionally explored the concatenation of action sequences, assuming the surprise factors that compose the narrative as the force that drives the act of reading. Readers keep reading because they are curious about what is about to happen. On the other hand, mangas focus on sensations. They explore emotional moments and turn readers into an essential part of the narrative. Raders are engendered in an empathic process that asks them to feel like the characters.

In The book of tea, Okakura recognizes such principle of abstraction as the result of a decisive influence of Zen on Japanese art. As a sort of worship of relativity, Zen assumes the mundane to be of equal importance to the spiritual. It proposes no distinction between minor or major events. Such a principle was appropriated from Tao. "The Present is the moving Infinity, the legitimate sphere of the Relative [...] The art of life lies in a constant readjustment to our surroundings" ("Taoism and Zennism", para. 8). Tao is the art of being. Taoism is this acceptance of things as they are; a search for beauty in our "world of woe and worry".

The Zen doctrine made possible the practice of Taoist aesthetic ideals, promoting a particular definition of perfection. It proposes that truth can be reached only through the comprehension of opposites; true beauty would be there only for those who are able to mentally complete the incomplete. In this sense, art (just like life) matters for its possibilities for growth. As Okakura explains, this "[...] philosophy laid more stress upon the process through which perfection was sought than upon perfection itself" ("The Tea-Room", para. 16). To avoid monotony and stagnation, and avoid ideals such as symmetry, uniformity, or self-regard, artists prefer to prioritize the depiction of landscapes, birds, and flowers over human figures (who are usually harmonically placed as part of nature or in contrast to the emptiness). 
"To the transcendental insight of the Zen, words were but an encumbrance to thought [...] The followers of Zen aimed at direct communion with the inner nature of things, regarding their outward accessories only as impediments to a clear perception of Truth" ("Taoism and Zennism" para. 14). As Okakura explains, the Zen tradition proposes the disposal of every excess or superfluity of information, which leads to a significant economy of verbal constructions. Therein, he also identifies the reason why many Zen artists preferred to express themselves through black and white sketches, with no use of colors or clear shapes. Zen art offers no room for redundancy. Artists preferred visual constructions over verbal ones, and sketch-like ideas over perfect realist depictions, thereby resembling abstract concepts. Both strategies have been widely explored by Japanese cartoonists.

\section{Japanese fluidity and rhythm}

Hoseki Shinichi Hisamatsu (apud Brinker) defines Zen art forms as being interested in the insignificance of life and common human experience. They are not sacred, coated with an official status, nor invested with any description or interpretation of practical nature, but they find themselves open to subjectivity, contemplation, and amplitude. Still echoing the principle of vacuum, Zen artworks do not signify something, they simply are. Moving toward more contemporary examples on how those principles seem to have been artistically translated into human productions, studies of Japanese cinema may also help us to understand mangas.

Lucia Nagib offers insight on the particular case of the cinematographic movement identified as the Japanese Nowvelle vague. Among the trends that particularized that set of Japanese films made in the 1960s, she emphasizes the depiction of youth. Those films present boys and girls in Western clothes, wandering with no destination, carrying their guitars, and getting into fights. Those are the mokusei eiga, movies with no nationality, in which errant individuals wander between their nation's identity markers and those from the West, in particular from the United States. They were more interested in knowing more about themselves than settling into one of the cultures.

Zen individuals are open to the observation of nature and the small details that make up its simplicity (Brinker). They are able to understand and act in an external world starting from their inner self, like the cinematographic characters from the Japanese Nouvelle vague seem to do. They live in movement, in a constant transition. As flaneurs, they, little by little, unveil the everyday delights ignored by others. On the reader`s side, they demand a deep 
emotional involvement. We are asked to feel like the characters more than to logically understand them. As Brinker argued, answers come through sensorial experiences and not through intellect.

Such a Japanese cinematographic movement, just like its French counterpart, broke up the boundaries between fiction and documentary. It created fragmented and asymmetric productions, inclined to chance and improvisation, far removed from any sort of strict attempt at control. Its protagonists are individuals in transit, always questioning themselves about the traditional identity markers that used to define the common Japanese subject, thereby turning it into a fluid body. They are neither the traditional Japanese citizen nor the Western stereotype they try to mimic. They are individuals who exist in between those two poles, constantly moving from one to another.

Looking at the technical choices that were common among those Japanese directors, Nagib highlights the regular use of faux raccords - borrowed from previous Yasujiro Ozu`s films - applied to apparently disjointed sequences or sequences with no continuity, which offers empty spaces to the spectators. Long shots - borrowed from Kenji Mizoguchi`s silent movies - were used to create slow and extended scenes. Despite those peculiarities, we can see that some features seem to be frequent among different generations of directors.

Sergei Eisenstein pointed out the notion of rhythm as the core issue in Japanese discursive constructions. His idea that cinema is fundamentally a matter of montage is already well known, but the main point here is the parallel he develops between the Japanese cinematographic principle and the notion of ideograms. Kanjis in general deal with concepts, especially if we agree that Chinese ideograms started from an iconic (in semiotic terms) relation to the world that users could grasp around them. In Eisenstein's terms, ideograms are a montage, or an articulation of possible combinations to produce something.

The arrangement of two ideograms creates not a simple sum of their meanings, but a new idea. They are a visual representation of abstract concepts, composed not by separate elements, but by a whole unit with proper logic. Every small detail is as relevant as the final idea, composing a complex asymmetric construct. Their principle is "denotation by depiction". Whether we look at Japanese writing, haikais, or pictorial art, there is a depictive aspect (by method) and a denotative aspect (by purpose), creating literary imagery to realize a given purpose. "As the ideogram provides a means for the laconic imprinting of an abstract concept, the same method, when transposed into literary exposition, gives rise to an identical laconism of pointed imagery" 
(Eisenstein 31). The dynamic of montage could be taken as a narrative propelling strategy, as a potential conflict, or an "imagist" transformation of this dialectical principle.

On the conflict between the frame/panel and the diegetic object, or on the way in which we look at something by framing it, the author highlights the common approach adopted by Japanese visual art schools to reveal how they have been organizing events in space (fig. 1). Such figurative composition prioritizes different aspects of the phenomenon. He emphasizes that this drawing approach shows (1) the detachment from an artificial spatial organization in clear and linear sequences and (2) the "picking out" nature of the monstrator ${ }^{2}$, expressing its unavoidable selective constitution. We have not the reality, but a possible one.

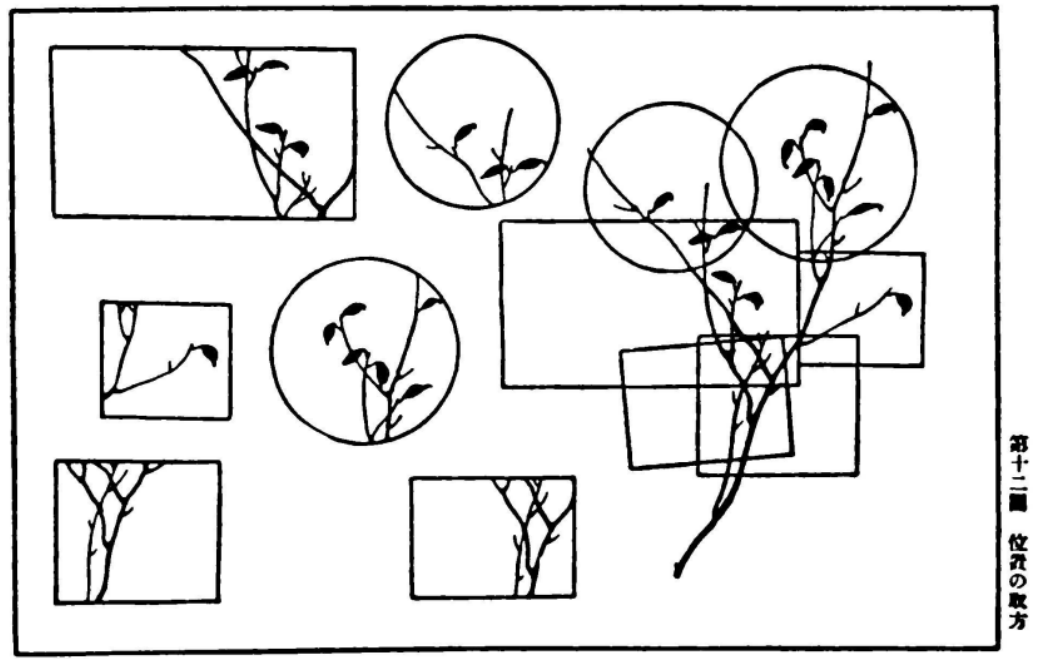

Fig. 1 - Japanese framing style, from Eisenstein (1949)

Eisenstein also discusses montage in Japanese theater, especially with regard to acting, which can also be useful in our understanding of mangas -as a certain Japanese artistic style. He introduces three features of Japanese acting: (1) the traditional "acting without transitions", (2) the principle of "disintegrated" acting, and (3) the use of a slow tempo:

\footnotetext{
${ }^{2}$ Following André Gardies's studies, the term "monstrator" is used to highlight the fact that if there is something the reader can see, it occurs because there is something being displayed. It is a choice of visual enunciation. Groensteen, building on Gardie's considerations, calls attention to the process of graphic narrative storytelling, in which the drawings are guided by the intention of the narrative. He uses the term as something that '[...] indicates the instance responsible for the putting into drawing [mise en dessin] of the story' ("The Monstrator, the Recitant", 4).
} 
- In the first feature, Eisenstein considers how actors characterize different degrees of emotional state only with mechanical cuts. As he says it, "Replacing one changing face with a whole scale of facial types of varying moods affords a far more acutely expressive result than does the changing surface, too receptive and devoid of organic resistance, of any single professional actor's face" (Eisenstein 42), creating a "distinct strengthening of the tension", a "play of doubts". Manga artists use similar strategies when drawing characters, like the "super-deformed" (SD) technique (Cohn), and its graphic emblems to express feelings and mood;

- In the second one, the author reflects on how Kabuki actors have roles in pieces of action detached from each other. Those actions work as successive pieces of acting, as when he describes the death interpreted by an actor, whose death agony disintegrates into solo performances of each of her members (head, arms, legs, and so on). The audience patiently follows piece by piece, action by action. In such a way, the work imposes a narrative flow and grips the spectator by "rhythms". A similar practice is also common in mangas (see fig. 2);

- Finally, in the third one, Eisenstein explains how, at some point, actors slow down all the movement. The strategy works as a slow-motion effect, in a disintegration of the moving process itself. Eisenstein believes that such unrealistic slowness usually implies a pictorial aim. There is also a significant increase in the intensity of perception.

\section{Looking at mangas}

Later in the 1990s, Thierry Groensteen would argue in favor of a definition of manga in accordance to Eisenstein's propositions. Groensteen evokes the idea of an art of montage, claiming that page layouts are organized in order to produce an aesthetic experience. The narrative moves (and time passes) because of the images' articulation. More than paying attention to what is depicted, to how drawings are displayed in connection to the rest, it is fundamental to understand how comics produce meaning. The Belgian scholar highlights, in particular, the ability mangas have to contract and expand dramatic moments in the narrative through an insightful display of panels and page layouts. The passage of time is then an elastic concept freely handled by artists in order to express feelings.

In their singular representation of time, "[...] les mangas se prêtent au jeu subtil de la réticence" (Morgan apud L'univers des mangas 43). Such use of time 
dilations generates emotional suspensions, contrasting with a certain rawness of action sequences. We can take, for example, pages produced by two Japanese authors, who examine the problems of the passage of time and contemplation. They work in different ways and each reflects the distinct issues we have presented in this paper. Our intention is to show how some of them seem to have been articulated in contemporary mangas.
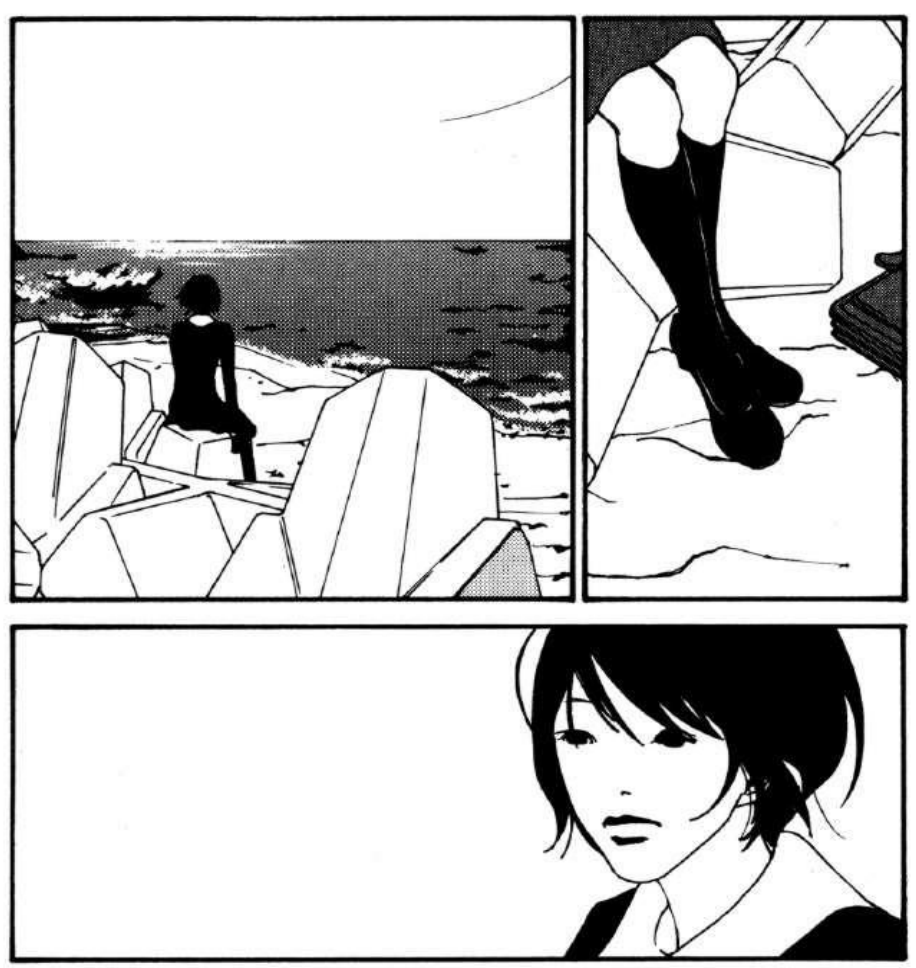

I'd like to come

here with Endo.

Fig. 2 - Notion of vacuum explored in Blue

In Kiriko Nananan's Blue, we have two high school students whose friendship turns into love. The plot covers their confusing teenage years, including fears and uncertainty about their current life and the future. 
Nananan's style is centered on minimalism, usually highlighting emotions, and includes a substantial use of silent panels. This particular page has three panels and a large white portion at the bottom (fig. 2). They depict one of the girls watching the ocean, lost in her thoughts. Nananan gives no space for superfluity, offering us layers of possible interpretations.

The use of contrasting black and white is essential, even if there is space for grey scale and some textures (as with the ocean or shadows). There is only the minimum to delineate the diegetic world, in a kind of rawness, as if heavy black elements were just floating in the white space. There are only simple forms, such as in the sketch of the character's face. The use of white is also significant. In Zen philosophy emptiness means that things in themselves are indefinable (Saito). We have merely a glimpse of such a diegetic world, having to instead imagine most of its features. It is basically constructed from black lines and a few gray textures. The motives are also scarce: the ocean, the girl, and the breakwater.

Looking specifically at Zen's contributions to the building up of Japanese culture, Suzuki points out the "one-corner" style, which originated with Bayen, and the "thrifty brush" tradition of retaining the fewest possible number of lines or strokes when representing forms. "A simple fishing boat in the midst of the rippling waters is enough to awaken in the mind of the beholder a sense of the vastness of the sea and at the same time of peace and contentment"; representing "[...] an appreciation of the transcendental aloofness in the midst of multiplicities" (22). Such incompleteness is an imperfection turned into a form of perfection. It evokes a sense of loneliness, which is fundamental to Zen art as it appeals to contemplation.

Suzuki associates the notion of asymmetry to Bayen's "one-corner" style , in which things would be accepted in their imperfection for their ability to realize the perfection in their peculiarities, rather than submitting them to an artificial symmetry. "The intellectual primarily aspires to balance, while the Japanese are apt to ignore it and incline strongly towards imbalance" (27). The imbalance is then essential in Japanese art. It is a matter of sensibility, not of intellect. In Nananan's example, we can see something similar. The page resembles both principles Suzuki evokes, dislocating the motifs from the center and reducing the number of strokes to a minimum, thus inviting us to take part in it.

In fact, the page is constructed as if, little by little, we could get closer to the character. Instead of feeling time passing by, we feel the opposite. The page depicts a sort of emotional suspension - or the "reticence" both Morgan 
(apud L'univers des mangas) and Eisenstein evoke. In a poetic approach, the page is constructed to focus on the girl's emotional state, through a "picking out" strategy like the one Eisenstein attributed to Japanese drawing schools. We see her back, legs, and then face as if we were approaching her. There are no elements indicating the passage of time, but the outline of an emotional experience, while the few concrete traces of the world (the ocean and the break water) disappear.
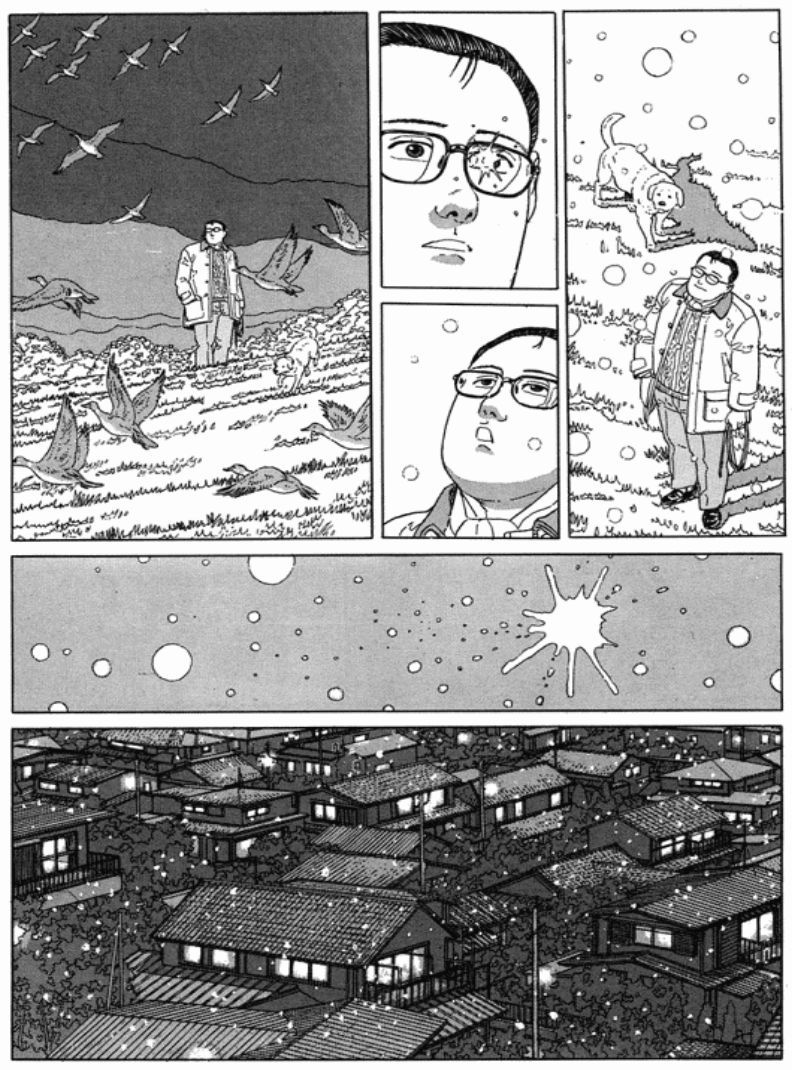

Fig. 3 - Daily moments and non-human centered events in The walking man

In opposition to Nananan's style, Jiro Taniguchi is more detail-oriented. We see a wide range of visual information, from nature to architecture. In the construction of the diegetic world (fig. 3), he seems to patiently draw rural or urban areas, carefully depicting nature, animals, buildings, and so on. His lines give shape to a particular world. Whereas the expressive use of contrasts characterizes Nananan`s work, lines and minutiae seem to be Taniguchi`s priorities. More than depicting an intimate (but universal) emotional moment 
in which readers take part, he offers the mundane world itself, a place rich in (in)significant trivia.

In The walking man, the main character is an unnamed protagonist who wanders around the city, chapter by chapter. After moving to an also unnamed city, he takes care of small daily activities, while paying attention to the ordinariness around him. In the page above (fig. 3), the man is calmly admiring wild ducks when he gets surprised by a snowflake hitting his glasses. The page starts with his contemplation and finishes with our own contemplation, as if the falling snowflakes become more important than him. We start moving away from the man to admire this natural event. This alternation between flâneur/voyeuristic moments, which characterizes the album, is shown as being part of life and daily activities. Unlike most of graphic narratives that focus on humans actions, Taniguchi displays characters as a simple elemental part of an intricate world.

Similar issues seem to appear in scholarship focused on the narrative depiction of everyday life. These trivia-centered narratives, inhabited by ordinary flâneurs, individuals usually driven by a pedestrian rhetoric, explore feelings of vagueness and repetition, as has already been pointed out by authors such as Ben Highmore and Michael Sheringham. As in Taoist principles, they embrace the vacuum of everyday life. Those characters accept that existence is permeated by transitions and fluidity - and their singular view of everyday life is then offered to readers. Those narratives are about the gaps displayed for the readers and explored by the flâneurs; about the indeterminacy of everydayness, which is constantly demanding our active participation.

Okakura proposes that moving through the vacuum is possible only to those who became the vacuum itself, which enables them to be in control over any situation. In the previous example, we can see, in particular, a similar attitude from the male character, which allows him to experience life through such a suspension. He assumes randomness as a guide to his unpretentious life. He extrapolates his own boundaries to feel the surrounding. It is not about "doing nothing", but about being able to do anything in accordance to the Taoist vision of experiencing life.

Readers are also asked to assume a similar non-goal-oriented posture. They are not invited to follow actions or big events, but are asked to have patience, to slowly accept what life offers. Unlike Nananan's example, Taniguchi invites us to step back and move far away from the character. The page shows more about the natural event than about him. In this asymmetric 
construction, the man seems to be no more than a strategy to call our attention to what happens with the weather.

\section{Manga-like narratives}

Rommens claims that reading manga is reading images. The sequential display is fundamental to their unique rhythmic style. The visual cues are the key to their interpretation, showing what happens in a less mediated way. This visual display works in opposition to the textual narrator, which is a common narrative strategy assumed by Western cartoonists. This visual turn is the main inspiration other cartoonists seem to have gained from their Japanese counterparts.

Mangas, regardless of their genre, usually have a high degree of variation in page layouts - in contrast to a more fixed Western tradition that claims an invisible medium. The detailed depiction of story settings can be seen in the previous examples, from Taniguchi's clearly labored style to Nananan's minimalist style. The balance between adding and hiding visual information is essential to Japanese art - and the composition of the page reflects it.

When searching for cartoonists who were influenced by mangas, Rommens looks at the way they seem to have intensified the visual narrative layer and reduced the presence of textual narrators, in order to avoid a redundant double enunciation. The visual turn in non-Japanese comics highlights the narrative depiction through visual information. Instead of following the narrators' verbal explanations and characters' statements, readers must see it and feel it. No wonder Western recipients have pointed out a certain "iconophilia" in Eastern productions (Rommens). We can see how some of those traits were translated in Gustavo Duarte's work, for example In his book Monstros!, a tale of a monster invasion in a Brazilian seaside town, the Brazilian cartoonist worked on some of the features pointed out by Rommens 


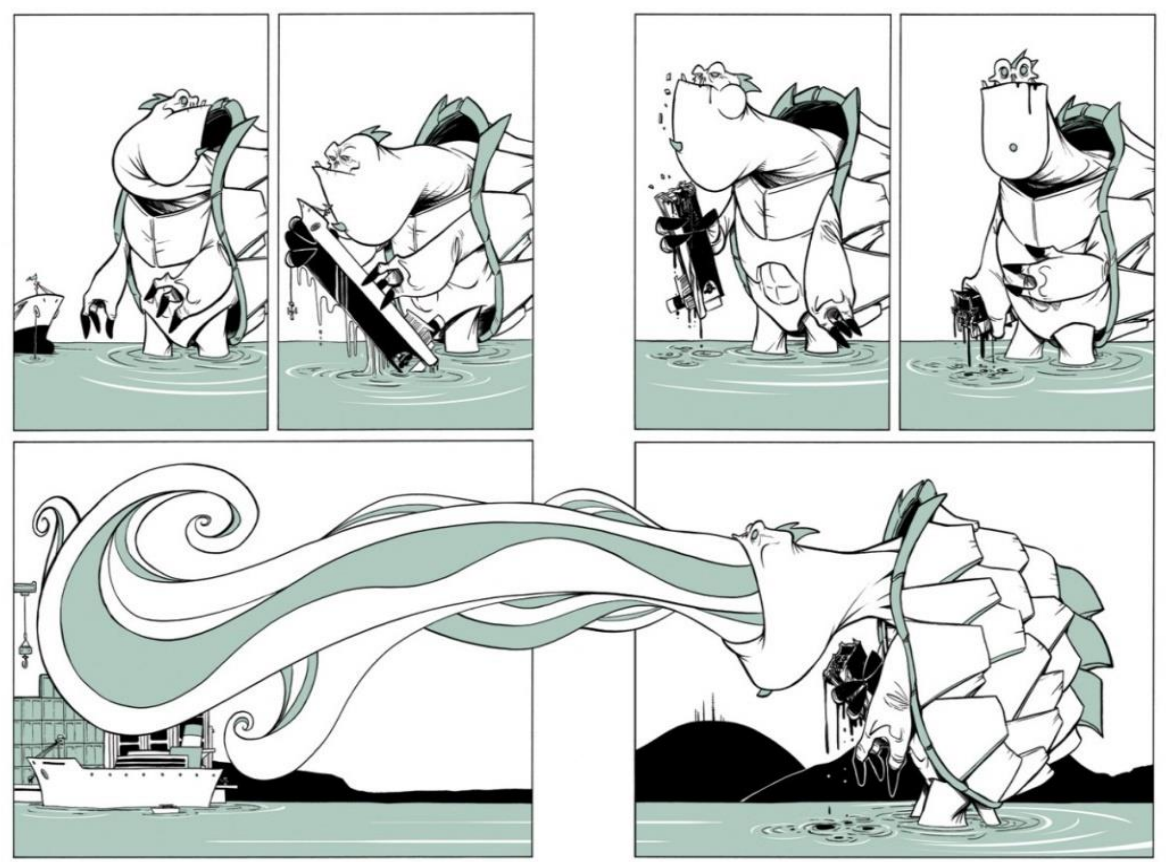

Fig. 4 - Use of visual narrative layer in Monstros!

The visual appeal highlighted by Rommens is clear. Duarte`s work is a silent adventure comic book that imposes a reading rhythm through its page layout and visual depiction. In this double-page extract, we can identify a simple art, similar to that of Nananan's story. Duarte prioritizes basic motifs as a way to capture the reader's attention. His depiction of time is also noteworthy. The action of grabbing the ship to eat it is divided into four stages, in which we can follow the monster's slow movements. Through this horizontal reading vector that guides this four-panel strip, the passage of time is extended until the monster realizes what it had just eaten.

It is also relevant to pay attention to how the cartoonist designed the pages to work as a unit organized according to two horizontal reading vectors: one from left to right (at the top of the page) and the other from right to left (at the bottom). The reader's gaze should then move in a sort of circular movement, going back and forth. The fluidity is also increased at the bottom. Here, time is perceived as moving faster. We have the same area that previously gave space to four panels condensed into two. In doing so, Duarte explores the dynamic between panels, even unifying the last two as if they were only one, which emphasizes the monster's reaction. Let us recall Okakura's discussion of the balance between the "part" and the "whole" in Taoist art; the 
artist controls work on the fragments of his narrative as much as the page itself. It is through this sort of visual strategy that the narrative guides the reader.

French productions seem to provide fruitful analyses of more examples of the way in which foreign artists were inspired by the Japanese story-telling style. Building on Benoit Peeters' concept of "rhetoric organization" of pages and panels, Groensteen (Bande dessinée et narration) identifies three main schools as part of Franco-Belgian comics history: the simple or classic rhetoric school, the sophisticated rhetoric school ${ }^{3}$, and the neo-baroque school (Le nouvean baroque). The latter seems to be part of such an encounter with Japanese stories.

In his words, the neo-baroque school deploys an arsenal of unsystematic effects to escape the monotony of any form or regularity. In the production of sense, the simple consecution of panels seems to no longer be enough, turning the device into something more "sophisticated", thanks to the emancipation, subordination, contrast, and stretching of panels. It is no longer about what to depict, but how. Groensteen traces the origins of the movement back to the 1970s, when comic artists started experimenting with the panel borders, moving towards an interpenetration of images opposed to the classical and canonical structure. If the traditional style sought simplicity and a so-called transparency in the composition of narratives, this new one prioritizes the dynamism and the enhancement of emotional effects.

One of the clearest cases is the nouvelle manga movement. A shortened version of "manga nouvelle vague", the label "nouvelle manga" was used at first to describe Boilet's graphic novels, which were curiously "[...] perceived by the Japanese as graphically close to BD but read like manga, and recalling the spirit of French cinema" (Boilet 1). The narratives were interpreted as an intersection between Japanese comics, French comics and films. Not long afterward, Boilet released an artistic manifesto pointing out the existence of nouvelle manga as an aesthetic proposal situated between mangas and bandes dessinées ${ }^{4}$.

\footnotetext{
${ }^{3}$ The first one concerns "discreet pages" in which panels follow the same regular structure. This composition bends the shape of the action to the action confined in it. On the other hand, the second school marks the distancing many authors adopted from the traditional model of linear reading vector, which has been used to characterize comic strips. Such a change was first analyzed by Fresnault-Deruelle through his concepts of "linearity" and "tabularity", when the horizontal vector gives space to vertical syntagms.

${ }^{4}$ See "On the everyday life: Frédéric Boilet and the Nouvelle Manga movement".
} 


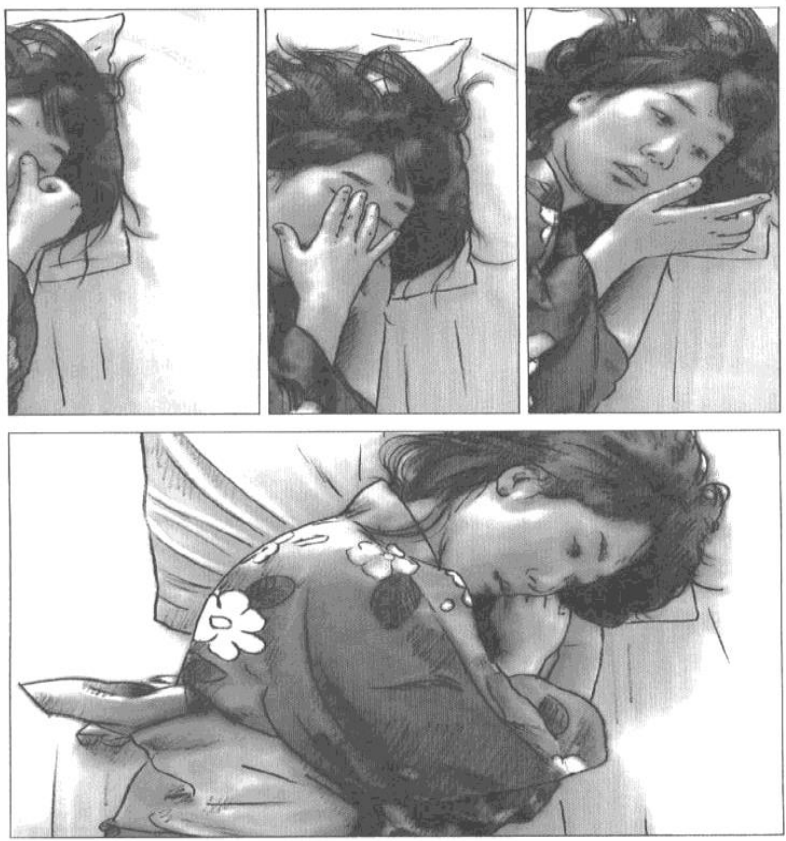

116

Fig 5 - Detailed depiction of everyday life in Yukiko's Spinach

Boilet's Yukiko's Spinach narrates the relationship between a cartoonist and a young Japanese woman, Yukiko. The narration underlines the lover's devotion by focusing on the girl's body, at the same time that turns the reader into the lover himself. The work demands readers to take such a position and admire her as much as the fictional lover does. We have no option but to contemplate her over and over in moments that are at the same time repetitive and unique, slowly looking at her small gestures framed in different instants through many panels. Since we are asked to fall for her, all about Yukiko becomes relevant. We observe her in the bed, rubbing her eye and laying down on the pillow, losing her gaze in an absolutely trivial moment (fig. 5). By dividing the first action into three panels, Boilet puts emphasis on it.

Following Okakura's ideas, we realize our place in the universe through the appreciation of such apparently insignificant moments of life. Taoism and Zen teach us how to look at the human experience from another perspective. Boilet, in his work, shows us something not different from this principle. He seems to propose the balance of love in "memorable events" as much as in the insignificant ones. If love is an everyday life experience, why would the ritual of waking up together be less important? As Zen proposes, life would be better conducted through the respect given to every small part of it. 


\section{Final words}

The discussion concerning the definition of manga is complex and makes room for a multiplicity of approaches. Moreover, each artist adopts different stylistic narrative structures and themes, which makes it even more difficult to find common features that unify their works. This paper aimed to instigate a philosophical approach to the study of manga through the contributions of Tao and Zen traditions to Japanese aesthetics.

Keeping in mind this sort of background, the debate on manga-like productions seems to extrapolate a simple search for the reproduction of a manga visual vocabulary, assuming that what is depicted and the way the narrative unfolds are absolutely important in the academic investigation of mangas. In sum, this paper proposes to focus on how we feel when reading those narratives. Observing the use of a particular vocabulary in the characters' design and the depiction of their expressions does not seem to be enough to single out a manga-like work. Other features should to be taken into account in the study of manga aesthetics, such as the reader`s experience.

Further scholarship is needed to analyze how principles such as fluidity, emptiness, and asymmetry have been used by different artists. The argument explored in this article does not restrict such strategies to Japanese culture, but they seem to be recurrent in Japanese art. Comparative study of various cultures could also investigate how these philosophical traditions have been translated into art by different societies. These strategies might be not exclusive to mangas, but are peculiarly explored in those narratives, and their aesthetic impression on Western readers could be assumed to be one of the reasons for their success.

The spreading of mangas around the world started decades ago. We are aware of the fact that since then a lot of experimental works have been published and narrative strategies have been incorporated and re-signified by many artists. On the other hand, Japanese artists have been influenced by foreign works and aesthetics for many decades. Thus, it is unlikely that one could clearly identify the origins of a given feature. However, we believe it is possible to talk about certain aesthetic strategies common to mangas, especially regarding the way in which they relate to readers. If it is not easy to say what originates from mangas, and what does not, looking at what nonJapanese works seem to have in common with the Japanese canon seems to be a fruitful approach. 


\section{Bibliography}

Abbott, Michael and Charles Forceville. "Visual representations of emotion in manga: Loss Of Control Is Loss Of Hands in Azumanga Daioh volume 4." Language and Literature 20, 2011, pp. 91-112.

Boilet, Frédéric. Nouvelle Manga in 2007. http://www.boilet.net/am/nouvellemanga_2006.html , 2007.

Brienza, Casey. "Introduction: manga without Japan ?" In Global Manga: "Japanese" Comics without Japan, edited by Casey Brienza. London: Ashgate, 2015, p. 1-22.

Brinker, Helmut. O zen na arte e na pintura, São Paulo: Editora Pensamento, 1995.

Canário, Tiago. "On the everyday life: Frédéric Boilet and the Nouvelle Manga movement". In Global Manga: "Japanese" Comics without Japan, edited by Casey Brienza. London: Ashgate, 2015, p. 115-132.

---. "The Labyrinth of Ordinary Experience: An Analytical Approach to the Construction of Everyday Life in Comic Books". In Epistémè, vol. 14, 2015, pp. 241-274.

Cohn, Neil. "Japanese Visual Language: The structure of manga". In Manga: An Anthology of Global and Cultural Perspectives, edited by T. JohnsonWoods. New York: Continuum Books, 2010, pp. 187-203.

Cohn, Neil and Sean Ehly. "The vocabulary of manga: Visual morphology in dialects of Japanese Visual Language”. Journal of Pragmatics. V 92, 2016, pp. 17-29.

Eisenstein, Sergei. "The cinematographic principle and the ideogram". In Film form: Essays in film theory". New York: HBJ Book, 1949, pp. 28-44.

Fresnault-Deruelle, Pierre. 'Du linéaire au tabulaire', In Communications, $\mathrm{n}^{\circ}$ 24, La bande dessinée et son discours, Paris : École dês Hautes Études en Sciences Sociales/Éditions du Seuil, 1976, pp. 7-23.

Gravett, Paul. Mangá: como o Japão reinventou os quadrinhos. São Paulo: Conrad, 2006.

Groensteen, Thierry. Bande dessinée et narration, Paris: Presses Universitaires de France, 2011.

---. L'univers des mangas: une introduction à la bande dessinée japonaise, Bruxelas: Casterman, 1991.

---. 'Les petites cases du moi: l'autobiographie en bande dessinée', In 9ème Art 1, 1996, pp. 58-83.

---. Le système de la bande dessinée, Paris: Presses Universitaires de France, 1999.

---. 'The Monstrator, the Recitant, and the Shadow of the Narrator', In European Comic Art, vol. 3 n 1, 2010, pp. 1-21.

McCarthy, H. (2009), The Art of Osamu Tezuka: God of Manga. New York: Abrams. 
McCloud, Scott. Desvendando os quadrinhos, São Paulo: M. Books, 2005.

Lamarre, Thomas. The Anime Machine: A Media Theory of Animation. Minneapolis and London: University of Minnesota Press, 2009.

Luyten, Sonia. Mangá, o poder dos quadrinhos japoneses, São Paulo: Hedra, 2011.

Miller, Anne. Reading bande dessinée: critical approaches to French-language comic strip, Bristol: Intellect, 2007.

Moliné, Alfons. O grande livro dos mangás, São Paulo: Editora JBC, 2004.

Nagib, Lúcia. Em torno da nouvelle vague japonesa. Campinas: Editora Unicamp, 1993.

Okakura, Kakuzo. (2008), The Book of Tea. http:/ /www.gutenberg.org/files/769/769-h/769-h.htm>

Peeters, Benoît, Lire la Bande Dessinée, Paris: Flammarion, 2008.

Saito, Yuriko. "The Moral Dimension of Japanese Aesthetics," In The Journal of Aesthetics and Art Criticism, 65.1, 2007, pp. 85-97.

Suzuki, Daisetsu Teitaro. Zen and Japanese Culture. Princeton: Princeton University Press, 1973 